\title{
Can Capsule Endoscopy Be Used as a Diagnostic Tool in the Evaluation of Nonbleeding Indications in Daily Clinical Practice? A Prospective Study
}

\author{
P. Katsinelos ${ }^{a} \quad$ K. Tziomalos ${ }^{a} \quad$ K. Fasoulas ${ }^{a} \quad$ G. Paroutoglou ${ }^{b}$ \\ A. Koufokotsios ${ }^{c}$ K. Mimidis ${ }^{d}$ S. Terzoudis ${ }^{a} \quad$ T. Maris ${ }^{e} \quad$ A. Beltsis ${ }^{e} \quad$ C. Geros ${ }^{b}$ \\ G. Chatzimavroudis ${ }^{a}$ \\ Departments of a Endoscopy and Motility Unit, G. Gennimatas General Hospital, Thessaloniki, b Gastroenterology, \\ University Hospital, Larissa, 'Endoscopy, General Hospital, Thessaloniki, ${ }^{\mathrm{I}}$ Internal Medicine, University Hospital, \\ Alexandroupoli, and ${ }^{\mathrm{e} G a s t r o e n t e r o l o g y, ~ G . ~ P a p a n i k o l a o u ~ G e n e r a l ~ H o s p i t a l, ~ T h e s s a l o n i k i, ~ G r e e c e ~}$
}

\section{Key Words}

Capsule endoscopy $\cdot$ Abdominal pain · Diarrhea •

Diagnostic yield

\begin{abstract}
Objective: To evaluate the diagnostic yield of capsule endoscopy (CE) and its impact on treatment and outcome in patients without bleeding indications. Subjects and Methods: One hundred and sixty-five nonbleeding patients were enrolled in the study. The most common indications for CE were chronic abdominal pain alone (33 patients) or combined with chronic diarrhea (31 patients) and chronic diarrhea alone (30 patients). Among the 165 patients, 129 underwent CE for evaluation of gastrointestinal symptoms and 36 for surveillance or disease staging. Results: CE findings were positive, suspicious and negative in $73(44.2 \%), 13$ (7.9\%) and $79(47.9 \%)$ of cases, respectively. The diagnostic yield was highest in patients with refractory celiac disease $(10 / 10$, $100 \%$ ) and suspected Crohn's disease (5/6, 83.3\%), followed by patients with chronic abdominal pain and chronic diarrhea (13/31, 41.9\%), established Crohn's disease (2/6, 33.3\%), chronic diarrhea alone $(8 / 30,26.7 \%)$, chronic abdominal pain alone $(8 / 33,24.2 \%)$ and other indications $(3 / 13,23.1 \%)(p<$ 0.005). The CE findings led to a change of medication in 74 $(47.7 \%)$ patients, surgery in $15(9.7 \%)$, administration of a
\end{abstract}

strict gluten-free or other special diet in $13(8.4 \%)$ and had other consequences in 11 (6.7\%). Management was not modified in $42(27.1 \%)$ patients. Among symptomatic patients $(n=129), 29$ (22.5\%) were lost to follow-up. The remaining 100 patients were followed up for $8.7 \pm 4.0$ months (range 2-19). Among the latter, resolution or improvement of symptoms was observed in $86(86 \%)$ patients, no change in 11 (11\%) and 3 (3\%) died. All 86 patients who experienced resolution or improvement of their symptoms had a modification of their management after $\mathrm{CE}$; only $7 / 11$ patients whose symptoms did not change (63.6\%) and $2 / 3$ patients who died (66.7\%) had a modification of management $(p<0.001)$. Conclusions: CE appears to be a useful tool in the evaluation of patients with nonbleeding indications. The outcome of most patients with negative findings was excellent.

Copyright $\odot 2011$ S. Karger AG, Basel

\section{Introduction}

Capsule endoscopy (CE) is a valuable tool in the investigation of gastrointestinal bleeding when upper endoscopy and colonoscopy do not reveal any abnormalities [1]. CE can be performed on an outpatient basis, does not require sedation, is noninvasive and allows the examination of the entire length of the small bowel [1]. CE

\section{KARGER \\ Fax +41613061234 \\ E-Mail karger@karger.ch}

www.karger.com (c) 2011 S. Karger AG, Basel

$1011-7571 / 11 / 0204-0362 \$ 38.00 / 0$

Accessible online at:

www.karger.com/mpp
Panagiotis Katsinelos, MD, PhD

Department of Endoscopy and Motility Unit, G. Gennimatas General Hospital Ethnikis Aminis 41

GR-54635 Thessaloniki (Greece)

Tel. +30 231096 3341, E-Mail gchatzimav@yahoo.gr 
has also been shown to be useful in other conditions, including Crohn's disease and familial polyposis syndromes [1]. The role of CE in the assessment of other nonbleeding indications and particularly in patients with chronic abdominal pain and/or chronic diarrhea is less clear [2-4]. Moreover, there are limited data on the impact of CE findings on patients' management and outcome [5-7]. In addition, the few existing studies in this area focused on patients with gastrointestinal bleeding [5-7].

The aim of this study was to evaluate the diagnostic yield of $\mathrm{CE}$ and its impact on treatment and outcome in patients with a variety of indications other than gastrointestinal-tract bleeding or iron deficiency anemia.

\section{Subjects and Methods}

All patients who underwent CE in five hospitals of Northern and Central Greece between January 2008 and January 2010 for indications other than gastrointestinal-tract bleeding or iron deficiency anemia were included in this prospective study. A total of 165 patients (male: 81 , female: 84 , mean age $45.9 \pm 16.7$ years, range 14-81) were studied. The indications for CE are shown in table 1 . The most common indications were chronic abdominal pain alone, i.e. lasting for at least 3 consecutive months (33 patients), chronic abdominal pain in combination with chronic diarrhea, i.e. lasting for at least 4 consecutive weeks (31 patients), and chronic diarrhea alone (30 patients). Among the 165 patients, 129 underwent $\mathrm{CE}$ for the evaluation of gastrointestinal symptoms and 36 for surveillance or disease staging (table 1).

Depending on the indication for CE, patients had previously undergone diagnostic procedures including colonoscopy, upper endoscopy, small bowel follow-through, computed tomography scan of the abdomen and/or magnetic resonance imaging scan of the abdomen, which were either negative or nondiagnostic. Also, depending on the indication, laboratory tests including inflammatory markers (erythrocyte sedimentation rate and C-reactive protein) were performed.

CE was performed on an outpatient basis, in the morning, after an overnight fast. All patients underwent CE only once. Bowel preparation was performed with 4 liters of polyethylene glycol solution given $15 \mathrm{~h}$ before CE. Patients were allowed to drink clear fluids $2 \mathrm{~h}$ after capsule ingestion and were instructed to maintain their normal activities during CE. Patients returned to the hospital $8 \mathrm{~h}$ after capsule ingestion and then the registration device and the antennae were collected. Five experienced endoscopists who had previously performed more than $200 \mathrm{CE}$ reviewed capsule video recordings. The location of small-bowel lesions was estimated by analyzing the CE transit time between pylorus passage and ileocecal valve. The duodenum was designated to be the small bowel that was visualized during the first $15 \mathrm{~min}$ after the capsule exited the pylorus, while the jejunum and ileum were designated to be the small bowel that was visualized after $<50 \%$ and $>50 \%$ of small-bowel transit time, respectively. The location of small-bowel lesions was also estimated based on the endoscopic appearance of the small intestinal mucosa (prominent folds and high narrow
Table 1. Indications for CE

\begin{tabular}{|c|c|}
\hline Indication & $\mathrm{n}(\%)$ \\
\hline Chronic abdominal pain & $33(20.0)$ \\
\hline Chronic abdominal pain plus chronic diarrhea & $31(18.8)$ \\
\hline Chronic diarrhea & $30(18.2)$ \\
\hline Established Crohn's disease & $6(3.6)$ \\
\hline Suspected Crohn's disease & $6(3.6)$ \\
\hline Refractory celiac disease ${ }^{1}$ & $10(6.1)$ \\
\hline Cirrhosis - suspected portal enteropathy ${ }^{2}$ & $9(5.5)$ \\
\hline Familial adenomatous polyposis ${ }^{2}$ & $15(9.1)$ \\
\hline Peutz-Jeghers syndrome ${ }^{2}$ & $7(4.2)$ \\
\hline Other & $18(10.9)$ \\
\hline Inflammatory bowel disease - unclassified ${ }^{2}$ & 1 \\
\hline Behçet's disease & 1 \\
\hline Weight loss & 2 \\
\hline Malabsorption syndrome & 2 \\
\hline Suspected leishmaniasis & 1 \\
\hline Suspected celiac disease & 1 \\
\hline Small bowel intussusception & 1 \\
\hline Liver metastatic disease of unknown origin & 1 \\
\hline Malignant ascites of unknown origin & 1 \\
\hline Gastric and duodenal carcinoids ${ }^{2}$ & 1 \\
\hline Fever of unknown origin & 2 \\
\hline Episodes of obstructive ileus & 1 \\
\hline History of neuroendocrine neoplasm ${ }^{2}$ & 2 \\
\hline Gastric lymphoma ${ }^{2}$ & 1 \\
\hline
\end{tabular}

${ }^{1}$ Persistent symptoms despite patient-reported strict adherence to gluten-free diet. ${ }^{2}$ Surveillance/staging group.

villi characterize the jejunum whereas fewer folds and shorter villi are observed in the ileum).

In the 129 symptomatic patients, the CE findings were classified as previously described [5, 7]: positive when they allowed a definite or probable explanation for the symptoms of the patient; suspicious when small-intestine lesions were detected but their relationship to the chief complaint was uncertain, and negative when there were no small-intestine abnormalities. In the 36 patients undergoing CE for surveillance or disease staging (e.g. patients with familial polyposis syndromes or with possible portal enteropathy), the CE findings were classified as positive and negative depending on the presence of relevant findings (e.g. polyps or portal enteropathy). The diagnostic yield of CE was defined as the detection of positive findings. Treatment and outcome following $\mathrm{CE}$ were recorded.

The study was conducted in accordance with good clinical practice, as set forth by the Helsinki agreements and their later amendments. The study was approved by our hospital's Ethics Committees and informed consent was obtained from all patients.

All data were analyzed using the SPSS (version 17.0; SPSS Inc., Chicago, Ill., USA) statistical package. The $\chi^{2}$ test was used for comparisons between groups. A p value $<0.05$ was considered statistically significant. 
Table 2. CE findings

\begin{tabular}{lclrr}
\hline Indication & $\begin{array}{l}\text { Positive } \\
\text { findings, } \mathrm{n}(\%)\end{array}$ & $\begin{array}{l}\text { Suspicious } \\
\text { findings, } \mathrm{n}(\%)\end{array}$ & $\begin{array}{l}\text { Negative } \\
\text { findings, } \mathrm{n}(\%)\end{array}$ & $\begin{array}{l}\text { Total, } \\
\mathrm{n}(\%)\end{array}$ \\
\hline Chronic abdominal pain & $8(24.2)$ & $3(9.1)$ & $22(66.7)$ & $33(100.0)$ \\
Chronic abdominal pain plus chronic diarrhea & $13(41.9)$ & $3(9.7)$ & $15(48.4)$ & $31(100.0)$ \\
Chronic diarrhea & $8(26.7)$ & $3(10.0)$ & $19(63.3)$ & $30(100.0)$ \\
Established Crohn's disease & $2(33.3)$ & $2(33.3)$ & $2(33.3)$ & $6(100.0)$ \\
Suspected Crohn's disease & $5(83.3)$ & $0(0.0)$ & $1(16.7)$ & $6(100.0)$ \\
Refractory celiac disease & $10(100.0)$ & $0(0.0)$ & $0(0.0)$ & $10(100.0)$ \\
Cirrhosis - suspected portal enteropathy & $7(77.8)$ & $0(0.0)$ & $2(22.2)$ & $9(100.0)$ \\
Familial adenomatous polyposis & $10(66.7)$ & $0(0.0)$ & $5(33.3)$ & $15(100.0)$ \\
Peutz-Jeghers syndrome & $7(100.0)$ & $0(0.0)$ & $0(0.0)$ & $7(100.0)$ \\
Other & $3(16.7)$ & $2(11.1)$ & $13(72.2)$ & $18(100.0)$ \\
\hline
\end{tabular}

\section{Results}

CE findings were positive, suspicious and negative in 73 (44.2\%), 13 (7.9\%) and 79 (47.9\%) of the cases, respectively. Therefore, the diagnostic yield of CE was $44.2 \%$. The rates of positive, suspicious and negative findings for each indication are summarized in table 2. In patients with chronic abdominal pain, positive findings included multiple ileal ulcers suggestive of Crohn's disease $(n=2)$, jejunal tumor $(n=1)$, ileal tumor $(n=1), 2$ ileal ulcers due to the use of nonsteroidal anti-inflammatory drugs (NSAID, $\mathrm{n}=2$ ), jejunal edema and erythema suggestive of ischemia $(n=1)$ and multiple ileal and jejunal ulcers suggestive of ischemia $(n=1)$ whereas suspicious findings included 1 small aphthous ileal ulcer $(\mathrm{n}=1)$, multiple ileal nodules $(\mathrm{n}=1)$ and ileal edema $(\mathrm{n}=1)$. In patients with chronic abdominal pain plus chronic diarrhea, positive findings included multiple ileal ulcers suggestive of Crohn's disease $(\mathrm{n}=10)$, jejunal tumor $(\mathrm{n}=1)$ and lymphangiectasia $(n=2)$ whereas suspicious findings included multiple small ileal ulcers $(n=1)$, few ileal ulcers $(n=$ 1) and focal jejunal and ileal erythema $(n=1)$. In patients with chronic diarrhea, positive findings included multiple ileal ulcers suggestive of Crohn's disease $(n=5)$, multiple jejunal and ileal ulcers due to NSAID use $(n=1)$, lymphangiectasia $(n=1)$ and villous atrophy suggestive of celiac disease $(\mathrm{n}=1)$ whereas suspicious findings included ileal polyp $(\mathrm{n}=1)$, jejunal polyp $(\mathrm{n}=1)$ and a small-ileal ulcer $(n=1)$. All 10 patients with refractory celiac disease had villous atrophy. In the 15 patients with familial adenomatous polyposis, polyps were identified in the duodenum, the jejunum and the ileum in 10,8 and 9 patients, respectively. All polyps were small $(<4 \mathrm{~mm})$ except for 3 duodenal polyps in a single patient, which were $>10 \mathrm{~mm}$.
Among the 129 symptomatic patients, the diagnostic yield was highest in patients with refractory celiac disease $(10 / 10,100 \%)$ and lowest in patients with other indications $(3 / 13,23.1 \% ; p<0.005$ between the various indications). In addition, the diagnostic yield was lower in patients with normal laboratory findings $(9 / 57,15.8 \%)$ compared with patients with elevated inflammatory markers $(17 / 29,58.6 \%)$, anemia $(1 / 2,50.0 \%)$ and anemia plus elevated inflammatory markers $(10 / 25,40.0 \%$; $p<0.001)$. Analysis of symptomatic patients by $\mathrm{CE}$ indication showed that the presence of anemia and/or elevated inflammatory markers was associated with a higher diagnostic yield of CE only in patients with suspected Crohn's disease and chronic abdominal pain plus chronic diarrhea ( $p<0.05$ and $p<0.001$, respectively). Finally, the diagnostic yield of CE was lower in symptomatic patients than in the surveillance/staging group (38.0 vs. $66.7 \%$, respectively; $\mathrm{p}<0.005$ ).

Management details following CE were not available in 10 patients (6.1\%). In the remaining 155 patients, management was modified in 113 (79.9\%) but not in 42 (27.1\%) patients. The modifications were as follows: change of medication in $74(47.7 \%)$ patients, surgery in $15(9.7 \%)$ patients, administration of a strict gluten-free or other special diet in $13(8.4 \%)$ patients and had other consequences in 11 (7.1\%) (in 6 patients colonoscopy was repeated, in 3 patients NSAIDs were discontinued, in 1 patient $\mathrm{CT}$ of the abdomen was repeated, and in 1 patient serum gastrin levels were determined). The rates of management modification differed significantly according to CE indication $(\mathrm{p}<0.001)$ and are shown in table 3. Thirty-seven patients with chronic abdominal pain and/or chronic diarrhea and normal CE findings were considered to have irritable bowel syndrome and were given 
Table 3. Rates of management modification by CE indication

\begin{tabular}{lc}
\hline Indication & $\begin{array}{c}\text { Management } \\
\text { modification }\end{array}$ \\
\hline Chronic abdominal pain & $28(87.5 \%)$ \\
Chronic abdominal pain plus chronic diarrhea & $30(100.0 \%)$ \\
Chronic diarrhea & $23(88.5 \%)$ \\
Established Crohn's disease & $4(66.7 \%)$ \\
Suspected Crohn's disease & $6(100.0 \%)$ \\
Refractory celiac disease & $10(100.0 \%)$ \\
Cirrhosis - suspected portal enteropathy & $0(0.0 \%)$ \\
Familial adenomatous polyposis & $3(20.0 \%)$ \\
Peutz-Jeghers syndrome & $2(28.6 \%)$ \\
Other & $7(50.0 \%)$ \\
\hline
\end{tabular}

symptomatic medical treatment. Therapy was changed in 7/11 patients with chronic abdominal pain and positive or suspicious $\mathrm{CE}$ findings and included a change of medication $(n=2)$, surgery $(n=3)$ and discontinuation of NSAIDs $(n=2)$. Therapy was changed in $16 / 16$ patients with chronic abdominal pain with diarrhea and positive or suspicious CE findings, and included a change of medication $(n=13)$, surgery $(n=1)$ and administration of a diet rich in proteins and medium-chain lipids (in 2 patients with intestinal lymphangiectasia). All 10 patients with refractory celiac disease were instructed to improve their adherence to the gluten-free diet. Management was altered in $51 / 73$ patients with positive CE findings (69.9\%), in $10 / 12$ patients with suspicious CE findings $(83.3 \%)$ and in $52 / 70$ patients with negative CE findings $(74.3 \%$; $\mathrm{p}=$ 0.59 ). When indications for CE were analyzed separately, there was also no association between CE findings and management modifications.

Among symptomatic patients $(\mathrm{n}=129), 29(22.5 \%)$ were lost to follow-up. The remaining 100 patients were followed up for $8.7 \pm 4.0$ months. At the last follow-up visit, resolution or improvement of symptoms was observed in 86 patients (86\%), no change in 11 patients (11\%) and 3 patients had died (after 2, 4 and 6 months, respectively; $3 \%)$. The latter 3 patients underwent CE for the evaluation of liver metastatic disease of unknown origin, malignant ascites of unknown origin and chronic abdominal pain plus chronic diarrhea, respectively. CE did not identify any abnormalities in the first 2 patients and diagnosed the jejunal adenocarcinoma in the third; however, the tumor was inoperable at laparotomy. Patients with chronic diarrhea or refractory celiac disease had the highest rate of symptom resolution (100\% in both groups; $20 / 20$ and $10 / 10$, respectively), followed by patients with chronic abdominal pain and chronic diarrhea (24/26, 92.3\%), suspected Crohn's disease (4/5, 80.0\%), other indications $(6 / 8,75.0 \%)$, abdominal pain alone $(19 / 26$, 73.1\%) and established Crohn's disease (3/5, 60.0\%; p < 0.001 between the various indications). All 86 patients (100\%) who experienced resolution or improvement of their symptoms had a modification of their management after $\mathrm{CE}$ whereas only $7 / 11$ patients whose symptoms did not change $(63.6 \%)$ and $2 / 3$ patients who died $(66.7 \%)$ had a modification of management after CE $(\mathrm{p}<0.001)$. Resolution or improvement of symptoms was observed in 44/47 patients with positive CE findings (93.6\%), in 9/11 patients with suspicious findings $(81.8 \%)$ and in $33 / 42$ patients with negative CE findings $(78.6 \%$; $\mathrm{p}=0.27)$.

CE was generally well tolerated even in adolescents. There was only 1 case of capsule retention in a 68 -yearold female who underwent CE for chronic abdominal pain. In this patient, $\mathrm{CE}$ revealed multiple nodules in the ileum. Surgery was required for the removal of the capsule and the pathologic examination of the resected part of the small intestine revealed multifocal carcinoid. The pain did not recur after surgery.

\section{Discussion}

The role of CE in the evaluation of patients with chronic abdominal pain and/or chronic diarrhea is unclear. Previous studies reported a relatively low diagnostic yield of CE in this setting [2, 4]. However, only one small study assessed the outcome of 16 patients undergoing $\mathrm{CE}$ for chronic abdominal pain [8]. The impact of CE on patients with chronic diarrhea alone or in combination with chronic abdominal pain has not been assessed before. In our study, most patients with chronic abdominal pain and/or chronic diarrhea and negative CE findings (78.6\%) showed improvement in their symptoms. Therefore, it appears that a normal CE limits the possibility of serious diseases such as Crohn's disease or small intestine tumors being present. Nevertheless, CE is still considered complementary in the evaluation of small-bowel pathology and can miss serious small-intestine pathology. Therefore, if there is a high index of suspicion or if symptoms persist, other imaging techniques should be considered, particularly computed tomography, magnetic resonance enterography and double-balloon enteroscopy [9].

In patients with suspected or established Crohn's disease and inconclusive findings on ileocolonoscopy, CE appears to be the imaging method of choice [1]. In our study, the diagnostic yield of CE was higher in patients 
with suspected than in those with established Crohn's disease ( 83.3 vs. $33.3 \%$, respectively). This might be because the latter patients received treatment and had no findings at the time of $\mathrm{CE}$. Even though $\mathrm{CE}$ findings are not very specific in Crohn's disease and we did not confirm these findings in all patients with other imaging modalities, most patients with suggestive CE findings who were given specific treatment for Crohn's disease responded to this treatment. Therefore, the possibility of false-positive CE findings is low but cannot be excluded. In patients with both established and suspected Crohn's disease, the detection of positive small-bowel lesions in CE results in modifications of management in most cases [10-12]. However, only a few small $(n \leq 23)$ studies reported outcomes following changes in treatment in established or suspected Crohn's disease and reported an improvement in most patients [10-14]. The small numbers of patients in the existing studies preclude definite conclusions, but it appears that CE-guided treatment leads to symptom resolution in the majority of patients with either established or suspected Crohn's disease.

Our study and previous reports [15-17] suggest that the presence of anemia and elevated markers of inflammation increases the diagnostic yield in patients with chronic abdominal pain and chronic diarrhea or with suspected Crohn's disease. Therefore, better selection of patients with gastrointestinal symptoms will likely improve the cost effectiveness of CE.

Current guidelines recommend that patients with refractory celiac disease should undergo CE [1]. The role of $\mathrm{CE}$ in these patients is complementary; when careful history and serological markers rule out noncompliance with gluten-free diet, $\mathrm{CE}$ is indicated for identifying complications such as cancer, ulcerative jejunitis or ileitis and other associated conditions such as collagenous sprue [1]. In previous studies in patients with celiac disease and persistent abdominal pain, CE was useful in revealing these complications $[18,19]$. In our study, no case of cancer or ulcerative jejunitis or ileitis was detected in the 10 patients with refractory celiac disease. The only CE finding in all these patients was villous atrophy, and implementation of strict gluten-free diet resulted in resolution of symptoms in all of them.

In the present study and in previous cohorts [20-23], CE identified polyps in most patients with familial adenomatous polyps and Peutz-Jeghers syndrome, and the majority of these patients underwent polypectomy. CE is currently considered a first-line examination for the surveillance of patients with Peutz-Jeghers syndrome and is also indicated in patients with familial adenomatous polyps when duodenal polyps are present [1].

The identification of portal hypertensive enteropathy is potentially important because gastrointestinal bleeding secondary to this condition is associated with high mortality [24]. In previous studies in cirrhotic patients, the prevalence of portal hypertensive enteropathy in $\mathrm{CE}$ varied between 63 and $68 \%$, which is similar to our findings (77.8\%) [25-27]. In our study and in previous reports, the identification of these lesions did not change patient management [25-27].

CE detected small-intestine tumors in 6.1 and $3.2 \%$ of patients with chronic abdominal pain and chronic abdominal pain plus chronic diarrhea, respectively. In another study that included 120 patients who underwent CE for nonbleeding indications, small-intestine tumors were diagnosed in $8.3 \%$ [28].

In conclusion, $\mathrm{CE}$ appears to be a useful tool in the evaluation of patients with chronic abdominal pain and/ or chronic diarrhea. The outcome of most patients with negative findings was excellent. In addition, patients with established and suspected Crohn's disease as well as those with refractory celiac disease also benefit from CE when indicated. Better selection of patients will increase the diagnostic yield and cost effectiveness of CE.

References ME, Rey JF, Niv Y, Delvaux M, de Franchis R, Costamagna G: European Society of Gastrointestinal Endoscopy (ESGE): Recommendations (2009) on clinical use of video capsule endoscopy to investigate small-bowel, esophageal and colonic diseases. Endoscopy 2010;42:220-227.

-2 Rondonotti E, Soncini M, Girelli C, Ballardini G, Bianchi G, Brunati S, Centenara L, Cesari P, Cortelezzi C, Curioni S, Gozzini C, Gullotta R, Lazzaroni M, Maino M, Mandelli G, Mantovani N, Morandi E, Pansoni C, Piubello W, Putignano R, Schalling R, Tatarella M, Villa F, Vitagliano P, Russo A, Conte D, Masci E, de Franchis R: Small bowel capsule endoscopy in clinical practice: a multicenter 7-year survey. Eur J Gastroenterol Hepatol 2010;22:1380-1386.

-3 Shim KN, Kim YS, Kim KJ, Kim YH, Kim TI, Do JH, Ryu JK, Moon JS, Park SH, Hee PC, Lee KM, Lee IS, Chun HJ, Jung IS, Choi MG: Abdominal pain accompanied by weight loss may increase the diagnostic yield of capsule endoscopy: a Korean multicenter study. Scand J Gastroenterol 2006;41:983-988. 
-4 Kalantzis N, Papanikolaou IS, Giannakoulopoulou E, Alogari A, Kalantzis C, Papacharalampous X, Gabriel P, Alexandrakis G, Apostolopoulos P: Capsule endoscopy: the cumulative experience from its use in $193 \mathrm{pa}-$ tients with suspected small bowel disease. Hepatogastroenterology 2005;52:414-419.

$\checkmark 5$ Kim S, Kedia PS, Jaffe DL, Ahmad NA: Impact of capsule endoscopy findings on patient outcomes. Dig Dis Sci 2009;54:24412448.

-6 de Graaf AP, Westerhof J, Weersma RK, Thijs WJ, Limburg AJ, Koornstra JJ: Correlation between predicted and actual consequences of capsule endoscopy on patient management. Dig Liver Dis 2008;40:761766.

7 van Tuyl SA, van Noorden JT, Stolk MF, Kuipers EJ: Clinical consequences of videocapsule endoscopy in GI bleeding and Crohn's disease. Gastrointest Endosc 2007;66:11641170.

-8 Spada C, Pirozzi GA, Riccioni ME, Iacopini F, Marchese M, Costamagna G: Capsule endoscopy in patients with chronic abdominal pain. Dig Liver Dis 2006;38:696-698.

-9 Sandrasegaran K, Maglinte DD, Jennings SG, Chiorean MV: Capsule endoscopy and imaging tests in the elective investigation of small bowel disease. Clin Radiol 2008;63: 712-723.

10 Lorenzo-Zuniga V, de Vega VM, Domenech E, Cabre E, Manosa M, Boix J: Impact of capsule endoscopy findings in the management of Crohn's disease. Dig Dis Sci 2010;55:411414.

-11 Dubcenco E, Jeejeebhoy KN, Petroniene R, Tang SJ, Zalev AH, Gardiner GW, Baker JP: Capsule endoscopy findings in patients with established and suspected small-bowel Crohn's disease: correlation with radiologic, endoscopic, and histologic findings. Gastrointest Endosc 2005;62:538-544.

12 Chong AK, Taylor A, Miller A, Hennessy O, Connell W, Desmond P: Capsule endoscopy vs. push enteroscopy and enteroclysis in suspected small-bowel Crohn's disease. Gastrointest Endosc 2005;61:255-261.
13 Fireman Z, Mahajna E, Broide E, Shapiro M, Fich L, Sternberg A, Kopelman Y, Scapa E: Diagnosing small bowel Crohn's disease with wireless capsule endoscopy. Gut 2003; 52:390-392.

14 Thomson M, Fritscher-Ravens A, Mylonaki M, Swain P, Eltumi M, Heuschkel R, Murch S, McAlindon M, Furman M: Wireless capsule endoscopy in children: a study to assess diagnostic yield in small bowel disease in paediatric patients. J Pediatr Gastroenterol Nutr 2007;44:192-197.

15 De Bona M, Bellumat A, Cian E, Valiante F, Moschini A, De Boni M: Capsule endoscopy findings in patients with suspected Crohn's disease and biochemical markers of inflammation. Dig Liver Dis 2006;38:331-335.

16 May A, Manner H, Schneider M, Ipsen A, Ell C: Prospective multicenter trial of capsule endoscopy in patients with chronic abdominal pain, diarrhea and other signs and symptoms (CEDAP-Plus Study). Endoscopy 2007; 39:606-612.

17 Valle J, Alcantara M, Perez-Grueso MJ, Navajas J, Munoz-Rosas C, Legaz ML, Cuena R, Carrobles JM: Clinical features of patients with negative results from traditional diagnostic work-up and Crohn's disease findings from capsule endoscopy. J Clin Gastroenterol 2006;40:692-696.

$\checkmark 18$ Daum S, Wahnschaffe U, Glasenapp R, Borchert M, Ullrich R, Zeitz M, Faiss S: Capsule endoscopy in refractory celiac disease. Endoscopy 2007;39:455-458.

19 Culliford A, Daly J, Diamond B, Rubin M, Green PH: The value of wireless capsule endoscopy in patients with complicated celiac disease. Gastrointest Endosc 2005;62:55-61.

20 Iaquinto G, Fornasarig M, Quaia M, Giardullo N, D’Onofrio V, Iaquinto S, Di Bella S, Cannizzaro R: Capsule endoscopy is useful and safe for small-bowel surveillance in familial adenomatous polyposis. Gastrointest Endosc 2008;67:61-67.
1 Katsinelos P, Kountouras J, Chatzimavroudis G, Zavos C, Pilpilidis I, Fasoulas K, Paroutoglou G: Wireless capsule endoscopy in detecting small-intestinal polyps in familial adenomatous polyposis. World J Gastroenterol 2009; 15:6075-6079.

22 Mata A, Llach J, Castells A, Rovira JM, Pellise M, Gines A, Fernandez-Esparrach G, Andreu M, Bordas JM, Pique JM: A prospective trial comparing wireless capsule endoscopy and barium contrast series for smallbowel surveillance in hereditary GI polyposis syndromes. Gastrointest Endosc 2005;61: 721-725.

23 Soares J, Lopes L, Vilas BG, Pinho C: Wireless capsule endoscopy for evaluation of phenotypic expression of small-bowel polyps in patients with Peutz-Jeghers syndrome and in symptomatic first-degree relatives. Endoscopy 2004;36:1060-1066.

24 Fix OK, Simon JT, Farraye FA, Oviedo JA, Pratt DS, Chen WT, Cave DR: Obscure gastrointestinal hemorrhage from mesenteric varices diagnosed by video capsule endoscopy. Dig Dis Sci 2006;51:1169-1174.

25 Canlas KR, Dobozi BM, Lin S, Smith AD, Rockey DC, Muir AJ, Agrawal NM, Poleski MH, Patel K, McHutchison JG: Using capsule endoscopy to identify GI tract lesions in cirrhotic patients with portal hypertension and chronic anemia. J Clin Gastroenterol 2008;42:844-848.

26 Figueiredo P, Almeida N, Lerias C, Lopes S, Gouveia H, Leitao MC, Freitas D: Effect of portal hypertension in the small bowel: an endoscopic approach. Dig Dis Sci 2008; 53 : 2144-2150.

27 De Palma GD, Rega M, Masone S, Persico F, Siciliano S, Patrone F, Matantuono L, Persico G: Mucosal abnormalities of the small bowel in patients with cirrhosis and portal hypertension: a capsule endoscopy study. Gastrointest Endosc 2005;62:529-534.

28 Cobrin GM, Pittman RH, Lewis BS: Increased diagnostic yield of small bowel tumors with capsule endoscopy. Cancer 2006; 107:22-27. 